Can M. Aybek \& Nadja Milewski

\title{
Introduction to the Special Issue on "Family migration processes in a comparative perspective"
}

\begin{abstract}
This paper provides an introduction to this Special Issue on "Family migration processes in a comparative perspective". Following an introduction to the topic, we provide summaries of the papers in this Special Issue and discuss afterwards some overarching theoretical perspectives. This Special Issue contains papers that explore how family lives and intimate relationships are constituted and re-constituted under conditions of transnationality. The authors of the contributing papers, although they have followed very different theoretical and methodological paths, underscore the effect of conducting and facilitating family life and couple relationships during or after an international migration process. They show that the couples and multigenerational families in transnational contexts are constantly undergoing processes of constitution, negotiation, and reconstitution. We conclude that future research should shift from focussing solely on the individual to examining couples and families, and it should adopt dynamic, rather than static perspectives when studying family migration.
\end{abstract}

\section{Preface}

Two years ago, in 2017, we received the generous offer to edit a Special Issue combining the research fields of family and migration. This was at a point in time when the word "Familienzusammenführung" (family reunion) was used - and also misused - in an inflationary manner in political and public discourses not only in our country, Germany, but also in other European states. By that time, nearly two years had passed since the large refugee influx from the Middle East and Northern Africa in 2015. In the meantime, we had witnessed how the question of family members who potentially might follow those who already had arrived in the country affected public debates about which and how many refugees under subsidiary protection are actually entitled to stay. Those debates undermine the premise that an individual who is subject to persecution is entitled to protection. Gender stereotyping featured prominently in the discourses on refugees, fuelled by the sexual assaults that occurred during New Year's Eve 2015/2016 in and around the central train station in the city of Cologne. A discourse analysis of reports published in two big news outlets in Germany (Süddeutsche Zeitung and Spiegel) in the years 2013 to 
2018 on refugees revealed that the keywords "male" and "young" were disproportionately mentioned together with the term "criminality" (Achterberg 2018). By contrast, "women" were mainly featured as potentially following family migrants with the primary role of ensuring that the male pioneer migrant can focus his attention on his successful integration into the host society. By successful integration, politicians mainly had in mind labour market participation - thus ignoring that asylum migration and labour demands in ageing Western societies may not perfectly match. The idea of the protection of the family as such appeared as a rather subordinated goal in public and political discourses. This illustrates the conflict area that arises when policies that target different goals interfere with each other. On the one hand, the family enjoys protection; on the other hand, immigration policies target individuals. By crossing international borders, the family is no longer only an institution in the private realm, but becomes a subject for controversial political debates (Bonjour/Kraler 2016).

Against this backdrop, we organized in October 2018 a workshop on family migration processes in Berlin. We wanted to establish a dialogue with and among those scholars who worked on topics related to family migration and could present results based on recent empirical observations. In this workshop, we also wanted to overcome typical compartimentalisations present in the academic world. We aimed to bring together scholars who come from various disciplines and countries, adopt different methodological perspectives, and focus on different "target groups".

Now, more than a year later, immigration to Europe continues, albeit on a smaller numerical level. New empirical studies have produced up-to-date datasets, and first results are available. We present five studies that fulfil our criteria of the initial idea of bridging different perspectives, methods, disciplines and - most importantly - research areas. Our main research interest is directed at the dynamics of family and couple life in a transnational context: We want to know how crossing international borders affects individuals as members of families or as partners, and how it affects families and couples as a whole, including those who stay behind.

Research on migration has come a long way in the past decades (Cooke 2008). Initially, the focus was on who moves and why. The (economic) research has mainly looked at the male migrant as the one initiating the international move, whereas another strand of research looked at the "trailing wife". Today we know that international migration involves not only individuals and couples, but also multi-generational households. Moreover, migration is a process that occurs over time (as in the case of refugees), includes much uncertainty and can consist of several moves; it need not be a single event that occurs over a short time span. Still, the majority of studies in this area are concerned with the questions of who moves and which determinants affect this move.

This Special Issue contains papers that explore how family lives and intimate relationships are constituted and reconstituted under conditions of transnational migration. The papers underscore the effects of conducting and facilitating family life and couple relationships during or after having experienced an international migration process. Within this scope, issues relating to integration or accommodation processes of immigrants and the problems they might have been confronted with on an individual level in their new homes do not make up the primary focus of these papers. This is partly due to the circumstance, highlighted also by Glick-Schiller (2010) and Levitt et al. (2003), that conditions 
in destination societies make up only part of the perspectives from which transnational families and couples look upon issues related to belonging, attachment or relatedness. Similarly, overemphasising the role of homeland communities of immigrants, in terms of imposing values and behavioural patterns with respect to how one should conduct intimate relationships or family life, would probably lead also to an incomplete picture about the dynamics of transnational social relationships. The authors who have contributed to this Special Issue, even though they have followed very different theoretical and methodological paths in their research, all focus in one way or another on decision-making and negotiation processes of individuals who have experienced family life or an intimate relationship in a transnational context. As a result, the main emphasis of the papers in this Special Issue is on the relational aspects of individual life courses and the family/relationship dynamics in transnational settings.

\section{Introduction to the papers of this Special Issue}

Leading an intimate partnership or family life across borders is often characterised by inequalities in wealth and status between the involved parties. Under such circumstances, certain activities of families may serve to compensate for these differences, for example by sending remittances to or trying to obtain visas for those who are in the disadvantaged position. Some economists (e.g. Stark/Bloom 1985) referred to the family or the household as the more appropriate unit of analysis -rather than individual migrants - to understand migration dynamics. Complementary research literature from various fields (Agoston et al. 2014; Bonjour/Kraler 2016; Bryceson/Vuorela 2002a; Kofman et al. 2011; Kraler 2014; Walter 2009; Williams 2010) also emphasises the need to contextualise the life of transnational families or couples by taking into account the conditions created by the state and by the respective local community.

On an empirical basis, of course, these different analytical levels might be interdependent by reinforcing or undermining each other. State authorities might have, for instance, very different ideas than immigrants and their communities about what constitutes a family or a legitimate partnership and who, at the end, should enjoy the right to join their family/partner living in another country. Studies have repeatedly addressed such issues and pointed out discrepancies or inconsistencies that occurred as a result of changing immigration policies (cf. Schrover 2009; Strasser et al. 2009). Strasser et al. (2009: 167) have argued that "[t]he conditions which the state imposes on the entry and stay of family members reflect a certain notion of family as a social institution, i.e. the state's perception of the family as a unit which mediates the relations between individual, society and state."

By regulating the migration of family members and spouses in terms of defining who has what rights and duties, nation-states draw a boundary between the public and private realm not only for certain individuals, but for the whole society. Regulations concerning (re)unification of families or partners from third countries, despite the aim to introduce common standards within the European Union (EU), differ considerably among member states (Berneri 2017). As pointed out in the papers by Kraus et al. and Ruis in this Special Issue, for instance, the impact of status differences between different groups of refugees 
in a specific national context defines the circumstances under which someone might enjoy the right for family reunification, employment or further education.

Legislation regulating the entry of family migrants has been changing in the course of time within individual nation-states in Europe. Political developments in the domestic and international realms often lead to tendencies to either liberalise or restrict policies (e.g. for Germany see Aybek 2012). By altering these rules, state actors respectively influence and change not only the rights of their residents with transnational family ties, but also the quality of the relationships among the members of these families. The same applies to the conditions for the entry of third-country citizens who want to join their partners living in an EU member state and are, as Bonjour and Kraler (2016) have shown, confronted with a range of different regulations stretching from quite liberal to very rigid depending on the country of destination. The intention of state actors behind such regulations is obviously to control and steer certain types of inflows. Individuals who are affected by such developments react to them by assessing their risks as families or couples and adapting their behaviour to newly introduced conditions (cf. Aybek et al. 2015).

Various dimensions of transnational migratory experiences have already been addressed extensively in migration research (e.g. Basch et al. 1994; Brah 1998; Cohen 1997; Smith/Guarnizo 1998; Faist 2000; Levitt/Waters 2002; Kibria 2002; Kasinitz et al. 2002). A part of that literature focuses on families and family lives in the transnational realm (Baldassar et al. 2007; Bryceson/Vuorela 2002b; Crespi et al. 2018; Goulbourne et al. 2011; Grillo 2008). The existing literature generally addresses how family life is sustained through networks across national borders connecting relatives and friends. A part of the scholarly work provides insights on how individuals and families try to cope with risks and challenges caused by external circumstances and political developments (Williams/Baláž 2012). Scholars emphasise that conducting familial life across national borders is nothing new; the phenomenon existed already in earlier periods (Bryceson/Vuorela 2002b; Goulbourne et al. 2011). Contemporary transnational migration experiences differ from those of earlier generations largely because of globalisation, advances in communication technologies, affordability of transportation, and the like (cf. Baldassar et al. 2007).

Since the early days of migration research, interethnic, bicultural or mixed partnerships and marriages have been among the standard areas of study (cf. Park/Burgess 1921 and other studies by representatives of the Chicago School). The continued interest in this topic stems from the fact that research on partner selection and marriage processes in the context of migration not only provides insights about the motivations and behaviour on the level of individuals, but also about how social boundaries between different groups within society are structured. In contrast to endogamous partnerships, which are viewed as the default option by a majority of groups in many societies and hence are affirmed by them normatively, exogamous relationships and marriages, especially with respect to partners who are ethnically, culturally and/or religiously different from each other, have often been considered unconventional and risky, and at times have been legally or socially sanctioned in different societies. Improved access to affordable transportation and communication technologies for wider parts of the population in the course of modernisation and globalisation have created more opportunities for individuals to meet people who are culturally, religiously or ethnically different to them. Couple relationships established between individuals from different ethnic-cultural, social and religious backgrounds create 
bridges across different parts of society and therefore serve as an important indicator for analysing current and future trends in these societies. The proportion of mixed-cultural partnerships and individuals with multiple cultural and/or ethnic affiliations within the general population increased over the last decades in European countries (Lanzieri 2012).

The papers assembled in this Special Issue aim to understand the dynamics of family and couple relations in their specific national and transnational contexts. The need for contextualising empirical projects is not only an exercise to secure well-grounded results, but is based also on the idea that commonalities of transnational family lives in different contexts can be better understood by taking into account the specifics of each context. However, to put transnational social ties into the centre of the research interest essentially requires trying to adopt the perspectives of those who are leading their family or couple life under such conditions. Relations among family members and intimate partners in a transnational context are influenced by residential mobility, spatial distance and reunification in a new place. To study the dynamics behind these processes essentially means to try to understand ,transnationalism from below“ (cf. Smith/Guarnizo 1998).

The first article by Christian Schramm, for instance, investigates the dynamics of change in transnational families in a migration system stretching from a former colony in Latin America to the former colonising country in Europe. The author draws on biographical perspectives of individuals from families that originate in Ecuador from which some members moved to Spain. The work is based on extensive multi-site fieldwork carried out in both the originating and destination countries of the migration project and with several members of the respective households. The data are innovative because they have a longitudinal character; the same family members were visited and interviewed on multiple occasions over several years. The author combines the life-course perspective with a family figurational framework. Through narrative biographical interviews, the author introduces the concept of turning points for the interpretation of individuals' actions. In doing so, Schramm is able to link actions and events on the individual level to the societal macrolevel, namely the economic crises that hit Ecuador at the turn of the millennium and Spain in the years 2008-14. The economic crisis in Spain also impacted the family members of immigrants in their countries of origin.

The second paper by Ada Ruis takes the reader to the refugee immigrants in Europe. The participants in her qualitative study originate from Syria and have settled in the Netherlands. Like Schramm, Ruis has worked for several years in the field, conducting interviews and collecting other data on multiple occasions. Also like Schramm, she is familiar not only with the receiving context, but also with the society of origin. Ruis focuses explicitly on gender-related aspects by asking how young Syrian women who came as refugees with their families to the Netherlands navigate between family and work. In order to explore this question she also applies the life-course perspective and combines it with the concept of turning points. She places special emphasis on individual status passages and linked lives both in couple formation, but also on intergenerational relations. This paper is interesting not only because it centres on women and their agency (and not on their role as tied migrants or trailing wives), but also because the women in this study are highly educated and seek to pursue family life as well as educational aspirations and labour force participation, thus combining elements of traditional gender roles and modern ideas of the family. 
The third paper by Elisabeth Kraus, Lenore Sauer and Laura Wenzel is again studying new refugee groups in Europe. The destination context in their study is, however, Germany, and the refugees originate from Syria, Afghanistan and Iraq, the three biggest refugee groups in Germany. Their paper is a quantitative study, which is still a novelty in social science research on vulnerable populations like refugees (Buber-Ennser et al. 2016; Kohlenberger et al. 2017). Their database is the IAB-BAMF-SOEP Survey of Refugees. The authors use the two available waves of data collection containing retrospective and prospective information. Their focus is on the migration practices of families, with the couple being the unit of analysis. Their main research question is what spousal migration practices look like, i.e., whether spouses can migrate together, and how this is influenced by other family members as well as by factors related to human and social capital and last but not least - their legal status. Kraus et al. show that forced migration is a gendered process and that several characteristics relevant for male migration do not apply to women.

While the papers mentioned above address mainly issues around family migration, the fourth paper authored by Giuseppe Gabrielli, Elisa Barbiano di Belgiojoso, Laura Terzera and Anna Paterno looks at individuals who undertook their international move alone. The receiving context of their study is Italy, which has a relatively short history as a modern immigration country, but which has experienced a rather large influx of foreigners given the short time span of immigration. Moreover, the immigrant population in Italy is highly diverse with respect to countries of origin and legal conditions; various quantitative data sources try to capture this diversity. Gabrielli et al. draw on data from the Survey on Social Conditions and Integration of Foreign Citizens and carry out event-history analyses on union formation after migration. This is innovative because it jointly models the impact of the length of stay in Italy and of the partner type, i.e. endogamous or exogamous partner choice. They find gendered patterns, with men being more likely than women to first become established in the labour market and then being more likely than immigrant women to form a mixed union with an Italian partner.

The fifth and last paper in this Special Issue also looks at the association between international migration and intimate relationships. Mirko Braack and Nadja Milewski focus on individuals in European countries who are part of an exogamous union, i.e., native Europeans who have a marriage or a non-marital cohabitation with a migrant. Unlike previous research on exogamy, they explore the native in such couples and ask whether their social attitudes toward family, gender and religion differ from that of other natives. The context of their study encompasses several European countries, both old and new immigrant destinations; the analysis is based on data of the Generations and Gender Survey. In so doing, they draw attention to the native part in such couples, for whom becoming part of a union or marrying an international migrant is not associated with a personal physical migration process, but with crossing social boundaries between population subgroups. Braack and Milewski question the common assumption that natives in exogamous studies are per se the vanguards in immigrant integration and the test of social cohesion. They show that such natives are a rather diverse group - like the immigrants - and that they combine traditional and modern cultural attitudes towards culture.

This short overview describes how the five papers presented in this Special Issue approach the topic of family and couple migration from different perspectives, in different 
origin-destination contexts and with different methodological approaches. Still, there are intersections between the papers with regard to theoretical perspectives that are addressed in the following section. Initially some migration types and their relation to family dynamics are critically discussed, focussing especially on dichotomies such as forced and voluntary migration. Next, two concepts discussed in the research about transnational families, namely 'frontiering' and 'relativising', are connected to the discussion about the importance of social networks for migrants. Finally, emphasising certain characteristics, the relevance of the life-course perspective for the papers in this Special Issue is thematised.

\section{Overarching themes of this Special Issue}

\section{Overcoming dichotomies}

The endeavour to delineate between different types of spatial mobilities in migration theory has led to the development of categories that are contrasted regularly with their 'counterparts'. This trend to dichotomise is observable when talking about voluntary vs. forced migration, international vs. internal migration or circular vs. unidirectional migration. Some of the papers in this Special Issue address the dynamics of family relations under the conditions faced by refugees, whereas the other papers do not have this focus. Hence the analyses contain forms of the phenomenon called forced migration as well as voluntary forms of migration. This raises the question of whether and how these contributions are substantively related to each other. In order to give a satisfying answer to this question, it seems worthwhile to provide some insights about the differentiations within migration research concerning different types of migration. For instance, Reed, Ludwig and Braslow (2016) point out that the label "forced migration" is used to denote various phenomena stretching from a flight due to acute conflicts and war to cases of human trafficking. They argue that the discursive dichotomy created between the terms "forced" and "voluntary" with respect to migration cannot be confirmed in a rigid manner on the level of empirical observation. If we describe migration as a process containing the stages leaving, travelling, transiting, arriving, settling, returning or moving onward, the forced or voluntary character of the decisions during these various stages might change and could also depend on how the available alternatives are interpreted (Bivand Erdal/Oeppen 2018; Carling 2017; Crawley/Skleparis 2018).

The papers by Kraus et al. and Ruis in this Special Issue address individuals and families who have had the experience of a flight, but do not put this circumstance necessarily in the centre of their analyses. The authors look rather at the dynamics of the family migration and the development of family relationships. In the analysis done by Kraus et al., for instance, the temporal dimension of family migration processes or the duration of spatial separation are the main focus. While studies on forced migration mostly focus on short-term effects, such as the immediate conditions and consequences of flight, Ruis's case studies contain important information about the medium- and long-term effects in terms of family life development. Such analyses, as presented here by Ruis, through 
which she illustrates the changes in inter- and intragenerational relations in a family after arrival in the Netherlands, show how 'doing family' functions in the destination society. 'Doing family' does not mean 'doing refugee family'; the family members aim at becoming independent of their initial legal status as refugees.

Nevertheless, from a legal perspective it is extremely important for individuals to meet the criteria contained in international agreements, such as the UN Convention of Refugees, as that is a precondition to obtain the refugee status. From a sociological point of view, however, if the motivations for migration are at the core of the matter, it does not seem to be sensible to make such a rigid differentiation between political and economic reasons.

To develop a comprehensive understanding of migration phenomena it seems to be more appropriate to take into account the various factors that simultaneously exert influence, as has been done by most authors in this Special Issue. This complex interaction of factors is even more relevant when looking at developments over a long period of time. Furthermore, from this point of view a rigid differentiation between voluntary and forced migration does not seem to be tenable.

Departing from classical sociological and (socio-)psychological theories that aim to explain human action (e.g. Ajzen 1996; Giddens 1984), people's behaviour takes place in a prestructured framework that restricts the options available in one way or another. In this manner, opportunity structures created on a societal level limit the scope of action on the level of individual autonomy. As Schramm illustrates, characteristics concerning roles and decision-making powers within family constellations determine the limits to the freedom of choice on an individual and familial level.

It is not possible in this introductory essay to discuss in more detail potential implications for the study of migration phenomena if the analytical perspective is strongly influenced by assumptions derived from action and motivation theories (cf. DeJong/Gardner 1981). We deem it sufficient to say that analytical models which are based on simplistic assumptions and rely exclusively on the orientations of actors to maximise benefits or utilities as explanatory factors do not seem to be very successful for grasping empirical realities. It seems more appropriate to assume that individuals make decisions based on many factors, not only pure cost-benefit analyses, and are, as is illustrated in the paper by Braack and Milewski in this Special Issue, for instance, also influenced to a certain extent by normative factors, such as value orientations, or follow long-term goals that are of non-monetary nature.

Rather than focussing on the voluntary or involuntary nature of migration processes, in our context it probably makes more sense to look at the degree of autonomy the actors enjoy and to talk about proactive vs. reactive patterns of behaviour (Richmond 1988). This agentic potential of individuals within families is also highlighted in the case studies presented by Ruis in this issue. Migration decisions, even if they have been taken under extremely high pressure, do not differ fundamentally from decisions taken under other social conditions. As stated above, any human action is subject to restrictions.

However, the range of options that are available differ from person to person, and depend on the resources accessible at the time. In other words, the autonomous character of decisions on an individual and collective level depends on the context. In certain situations, it seems feasible and appropriate to take a decision to migrate or not, once all avail- 
able information has been critically assessed and the tangible and intangible benefits and risks that might go along with a migration have been weighed. In other situations, however, decisions to migrate might have more the character of a panic reaction induced by crises.

On the level of families, therefore, one might delineate between reactive and proactive strategies for action, as proposed by Richmond (1988). A comparative reading of the papers in this issue authored by Schramm and Ruis, even though dealing with non-refugee and refugee contexts, reveals interesting commonalities with respect to the autonomy of actors within family networks. Such a reading also illustrates that in most cases the empirical reality probably lies between these two poles of reactive and proactive strategies of action. Furthermore, the cases presented in the two papers illustrate that the decision to migrate is generally not taken abruptly. Rather, the individuals and families have been confronted for a relatively long period of time with the erosion of social structures, have experienced crises in terms of policies, security and economy and have been unable to satisfy the most important needs on an individual and familial level.

For Castles (2003) such patterns of spatial mobility have to be seen within the framework of deepening inequalities between the Global South and North. Inclusion and exclusion processes that have been triggered by globalisation processes, he argues, lead to conflicts and, ultimately, to migratory movements where it is difficult to distinguish clearly between security-related and economic motives (see also Zolberg 2001). Already in the early research literature emphasising the transnational character of migration (Faist 2000; Basch et al. 1994; Portes 1999; Vertovec 1999), the classical push-pull models to explain migration have been criticised. Main points of critique directed towards mainstream migration researchers has been that they overemphasise the role played by nation-states and their perspective on migration processes is that of movements in closed spatial contexts dominated by these nation-states. The transnational perspective, in contrast, departs from the idea of transnational social spaces transcending national boundaries and emphasises the role played by the exchange and circulation of different types of capital as well as networks across these boundaries connecting migrant and non-migrant populations.

Against this background we stress the importance of looking at commonalities between refugee families and non-refugee immigrant families by adopting a synthesising perspective of looking at transnational family constellations.

\section{Overcoming boundaries}

By way of introducing another analytical perspective that is relevant for several papers in this Special Issue, we present two concepts, 'frontiering' and 'relativising', that are discussed in the research literature on transnational families (Al-Sharmani et al. 2017; Bryceson/Vuorela 2002; Goulbourne et al. 2011; Grillo 2008). These concepts capture important aspects with regard to the dynamics of intra-familial relations in a transnational context and, at the same time, take into account the interaction of such families with their social environments.

The first concept, 'frontiering', highlights the means by which individuals interact with their family networks and within their transnational environment. Bryceson and 
Vuorela (2002) attribute a relevance to this term that differs from the meaning expressed when social relations are negotiated. In contrast to negotiating, frontiering refers to the interactions within families and between family members and external actors and, depending on the situation, these interactions could be to a greater or lesser degree consensual or conflictual. Conflictual interactions are characterised in this sense by behaviour that aims to obtain a greater clarity about attributions, differences and similarities, and results in social roles and positions that are rearranged accordingly. In this sense, 'frontiering' means to develop a common understanding during interactions of where to draw boundaries.

Bryceson and Vuorela (2002) emphasise that their use of the term 'frontiering' should be clearly disassociated from its historical meaning, related to the colonisation of North America, that entails the conquest and expropriation of 'the others'. In their perspective, the concept is used to describe how interactions in the liminal space between different life worlds are structured. 'Frontiering' in the sense used by them is an agentic concept that helps avoid falling into the trap of a Eurocentric viewpoint. It represents a counter perspective to assimilation theories concerning immigrants; instead the term denotes that acculturation processes are very variable and open-ended. This proposition is made against the background of historical changes that since the second half of the 20th century turned Europe from an emigration into an immigration continent, characterised by a population that is - at least in its urban conglomerations - increasingly diverse (Vertovec 2007).

In the course of modernisation and globalisation, growing opportunities as well as necessities concerning spatial mobility within European societies have led to an increase of pluri-local family structures. In such families solidaristic relations and shared responsibilities, however, are not weakened and have not become rudimentary, but need to be organised differently to adapt to changing conditions (Baykara-Krumme 2013; Mau 2007). Frontiering refers, at this point, to processes of accepting or rejecting certain behavioural patterns and normative orientations both within transnational families as well as in the wider society. Under conditions of transnational migration, experimenting with new familial roles and norms, adapting these, or trying to preserve existing roles and norms could, depending on the specific conditions, all lead to confrontations between genders or generations within a family (Bryceson/Vuorela 2002: 11-16). These processes may also result in a new consensus about altered roles and responsibilities within families (cf. Nauck 2005 and the papers by Ruis, Schramm and Braack/Milewski in this Special Issue).

The second concept Bryceson and Vuorela (2002) introduce in the context of transnational family relations is 'relativising'. This concept is used to indicate the various possibilities individuals have to establish, sustain or limit their relations with other family members. Relativising entails the behaviour through which bonds between family members in a transnational context may be fortified or weakened. Who is being seen as a communication partner within a family may be subject to change in the course of time. The pluri-local dispersion of the family and the existing geographical distances, make it necessary for transnational migrants to put effort into perpetuating and refreshing relationships with other family members. The concept of 'relativising' serves the purpose, according to Bryceson and Vuorela (2002: 14-15), of underscoring that, similar to the mechanisms described by Anderson (1983) concerning the construction of nations as imagined communities, 'doing family' in a transnational context requires actions that reconfirm emotional bonds and define shared responsibilities and hereby (re)construct family life. 
Due to spatial distance between family members, these often do not have the opportunity of spontaneous personal interaction on a daily basis. As a result, a necessity to 'organise' connectedness among family members occurs that has to be adapted to the emotional needs and available material and time-related resources. Relativising also means, in this sense, that family identities change and individuals constantly need to redefine their own role within the family. The qualitative cases analysed by Ruis and Schramm in this Special Issue represent good illustrations of such dynamics.

\section{Overcoming static and single-level research perspectives}

As the contributions to this volume relate in one way or another to a perspective from life course research, it seems worthwhile to recall the features of this perspective: Since its beginnings, life course research has not been considered to be a scientific branch in itself, but instead is characterised by a high degree of interdisciplinarity (Giele/Elder 1998; Mortimer/Shanahan 2003). Depending on the focus of investigation, different disciplines, such as sociology, ethnography, history or historical demography or (developmental) psychology, may represent the main frame of reference. Researchers who follow a life-course research approach often employ concepts such as transitions, trajectories, turning points, spacing or age norms in combination with sophisticated empirical methods (Mortimer/Shanahan 2003). Among the first was Glen Elder (1973; 1974; 1993), who tried to describe the life course research paradigm as a set of theoretical and empirical elements combined for the purpose of reaching a better understanding of societal dynamics by simultaneously considering individual biographies and macro-social influences.

Despite the diversity of studies in this context, Elder et al. (2003) break down the characteristics of this research approach into four shared principles: First, the life-course perspective consistently holds the idea that sociological, psychological or biological processes in human societies are subject to permanent changes on the intra- as well as the interpersonal level. The feature that distinguishes life course research from other socioanalytical approaches is not the specific premises put forward, but rather the perspectives that the approach offers. The gist of these perspectives, adopted in the papers gathered in this Special Issue, essentially can be traced back to a study of migration research that is considered to be a classic, namely "The Polish Peasant in Europe and America" by Thomas and Znaniecki (1918-1920). Although the methodologies adopted in the contributions to this volume differ, the dynamic perspective is a characteristic they share.

Second, by focussing on the concept of agency, the life course perspective also highlights the possibilities of individuals to influence, according to their abilities and within the limits set by their environment, the conditions individuals themselves and those who are close to them are subjected to (Bandura 2009). Emphasising the role of agency helps scholars stay alert with respect to the risk of too quickly interpreting correlations they may observe on the aggregate level as causal relationships presumably valid for all immigrants of a certain type. How relations among couples or family members develop is to a great extent a consequence of decisions taken and actions performed by the very persons who are part of these relations. As also illustrated, for instance in the papers authored by Schramm and Ruis in this Special Issue, individuals regularly aim to impact their (inti- 
mate) relations in a way that suits their interests and goals in order to secure their own well-being and that of those who are dear to them. The actions they take are restricted by the resources that are available to them; these actions have to be coordinated with the goals the individuals follow in other realms of life and are generally regulated by institutions and other structural conditions. The concept of 'agency' draws attention to the fact that behaviour under such circumstances is still formed by subjective preferences based on previous biographical experiences.

And third, the life course perspective underscores that social processes take place at a specific moment in time and in a particular geographical location. Within this framework, time has not only relevance as chronological time, but also as biographical time, i.e. the point in time at which certain events and processes occur in the life of a person. This is particularly relevant for the migratory processes individuals experience. Jasso (2003: 331) stresses that " $[\mathrm{a}] 11$ the processes associated with migration are rooted in time. They occur in particular historical eras and bear the imprints of those eras. They occur at different ages and bear the imprints of those ages. How difficult it was to migrate, how successful the migration, how permanent the move - all these depend jointly on the historical context and the migrant's age. Of course, many other factors shape the migration process, including, importantly, conditions and laws in both the origin and destination countries and including as well the migrant's enduring endowments and characteristics."

These issues are particularly relevant for analysing processes concerning families and couples in a transnational context, because they illustrate the types of interdependencies that exist between processes on global, local and individual levels. Life-course researchers are generally not interested in biographies of particular individuals, but rather search for systematic patterns that emerge due to events and transitions in specific life stages; they consider the impact of such questions as when and whom to marry (cf. Gabrielli et al. in this Special Issue) or how one's schooling is interrupted by fleeing from a war zone (cf. Ruis in this Special Issue). The analytical lenses provided by life course research help to assess the similarities and differences between experiences made by transnational families and couples in contrast to those who do not have a migratory background (cf. Braack/ Milewski \& Gabrielli et al. in this Special Issue). The fourth shared principle emerges from this perspective: 'Linked lives' appears as a concept to indicate that individual life courses are shaped by the social networks in which individuals are embedded, as well as by events on the macro-societal level. The analyses presented, for instance by Schramm in this issue, emphasise the role external shocks may have on transnational familial relations.

This approach of trying to embed the dynamics of individual life courses into broader societal contexts leads to an analytical perspective that Huinink and Feldhaus (2009: 307f.) describe as follows: "The life course is embedded in a multilevel structure of social dynamics and individual development. On the one hand, individual well-being is influenced by a multilevel frame of external and internal conditions. On the societal level, cultural and institutional social structures as well as political and economic conditions determine the constraints and opportunities of social action. On the level of the social context and social networks, associations, neighbourhoods, family and partnership (dyadic level) influence the scope of context- and situation-related actions of interdependent actors to differing degrees. ... On the individual level, we must consider the individual re- 
sources and the psychosocial dispositions of the actor, which work as internal conditions of action. On the other hand, individual action feeds back into the process of reproducing and changing the social structure on every level. It affects individual resources and causes modifications of psychosocial dispositions."

The application of the life-course approach to migration research enlarged the thematic scope to interrelations of events in the life course, such as the impact of moving on union stability or the interrelation of migration and family formation (Kulu/Milewski 2007). A drawback of the life-course approach in quantitative studies is that it tends to focus on one single event at a time. Recent research has tried to solve this by using techniques of sequence analysis and looking at trajectories instead of single events (e.g., Kleinepier et al. 2015). Still, the focus here is on the individual. A newer, growing body of literature looks at the family life of several family members within a household. This is exactly where our Special Issue makes a contribution.

\section{Summary conclusions and implications for future research}

The contributions to this Special Issue come from researchers who are based in different countries and use data from these contexts. Cutting-edge empirical research is brought together that closes important gaps in our knowledge on transnational couples and families. This Special Issue contains five empirical studies that target the notion of family from a variety of theoretical, analytical and methodological perspectives. It is thus not surprising that the picture of 'family' is a diverse one. This diversity is not caused by the diversity of the perspectives, but by the causes and consequences of migration phenomena under conditions of globalisation. In fact, it is a joint feature of all these different families in transnational settings that they are constantly subject to change. The families not only differ from each other, they constantly change in their constellations, locations and relations. Our Special Issue and the review of the literature suggest that it is worthwhile for future researchers to transcend the boundaries between their disciplines or their methodological paradigms, similar to what the families and couples studied do on an almost daily basis in overcoming spatial, legal and social boundaries.

An improved understanding of the dynamics of couple and family relations in the context of migration is urgently needed, as the issues discursively addressed are socially and politically relevant on different levels of society. It seems to be particularly important to look only not into the causes of international migration, but also at subsequent migratory events (such as chain migration) as well as at the social integration of immigrants in their new environment. Furthermore, many researchers implicitly suggest that the native population in the destination country plays a role in immigrant integration, but studies combining both perspectives are rather rare. Concepts like 'frontiering', 'relativising' (Bryceson/Vuorela 2002b) or 'boundary making' (Lamont 2014; Wimmer 2008; 2013) should be applied to both parts in migration contexts, the ones who move and the ones whose environment changes due to migration without having physically moved.

Having said this, the papers in our Special Issue suggest most importantly that future research should broaden its perspectives by not focussing solely on the individual, but 
studying also couples and families. As these transnational couples and multigenerational families are constantly undergoing processes of constitution, negotiation and reconstitution, adopting a dynamic instead of static analytical perspective seems appropriate. We are aware that our suggestions for future research would also require substantial efforts in data collection.

\section{Acknowledgements}

We thank the editorial office of the Journal of Family Research for letting us organize this Special Issue. To prepare it, we organized a workshop on "Family Migration Processes in a Comparative Perspective: Causes, Patterns, Effects", which took place on 25 October 2018 at the WissenschaftsForum in Berlin in collaboration with the German Society for Demography. We thank the collaborators, the participants in the workshop, the authors of the contributing papers as well as several anonymous reviewers for their constructive discussion and helpful comments on the papers.

\section{References}

Achterberg, M. (2018). Familiennachzug im Diskurs: Eine Mixed-Methods Analyse der Online-Berichterstattung in Deutschland von 2013 bis 2018. Rostock: Institut für Soziologie und Demographie. Rostock (Master's thesis).

Agoston, A., Hutton, J. \& Wray, H. (2014). A family resemblance? The regulation of marriage migration in Europe. European Journal of Migration and Law, 16, 2, pp. 209-247. doi: $10.1163 / 15718166-12342054$.

Ajzen, I. (1996). The social psychology of decision making. In: Higgins, T. E. \& Kruglanski, A. W. (Eds.), Social psychology. Handbook of basic principles. New York, N.Y., London: The Guilford Press, pp. 297-325.

Anderson, B. R. O.'G. (1983). Imagined communities. Reflections on the origin and spread of nationalism. London: Verso.

Aybek, C., Straßburger, G. \& Yüksel-Kaptanoğlu, İ. (2015). Marriage migration from Turkey to Germany: Risks and coping strategies of transnational couples. In: Aybek, C., Huinink, J. \& Muttarak, R. (Eds.), Spatial mobility, migration, and living arrangements. Cham: Springer, pp. 23-42.

Aybek, C. M. (2012). Politics, symbolics and facts: Migration policies and family migration from Turkey to Germany. Perceptions - Journal of International Affairs, 17, 2, pp. 37-59.

Baldassar, L., Baldock, C. V. \& Wilding, R. (2007). Families caring across borders. Migration, ageing and transnational caregiving. New York: Palgrave Macmillan.

Bandura, A. (2009). Agency. In: Carr, D. S. (Ed.), Encyclopaedia of the life course and human development. Detroit, MI: Macmillan, pp. 8-11.

Basch, L. G., Schiller, N. G. \& Szanton Blanc, C. (1994). Nations unbound. Transnational projects, postcolonial predicaments, and deterritorialized nation-states. Langhorne: Gordon and Breach.

Baykara-Krumme, H. (2013). Generationenbeziehungen im Alter: Türkische Familien in der Türkei und in Westeuropa. Zeitschrift für Familienforschung/Journal of Family Research, 25, 1, pp. 9-28. https://www.budrich-journals.de/index.php/zff/article/view/12412/10796 [retrieved November 16, 2019].

Berneri, C. (2017). Family reunification in the EU. The movement and residence rights of third country national family members of EU citizens. Oxford, UK: Hart Publishing. 
Bivand Erdal, M. \& Oeppen, C. (2018). Forced to leave? The discursive and analytical significance of describing migration as forced and voluntary. Journal of Ethnic and Migration Studies, 44, 6, pp. 981-998. doi:10.1080/1369183X.2017.1384149.

Bonjour, S. \& Kraler, A. (2016). Family migration and migrant integration. In: Triandafyllidou, A. (Ed.), Routledge handbook of immigration and refugee studies. London, New York: Routledge Taylor \& Francis Group, pp. 153-159.

Brah, A. (1998). Cartographies of diaspora. Contesting identities. London: Routledge.

Bryceson, D. F. \& Vuorela, U. (Eds.) (2002a). The transnational family. New European frontiers and global networks. Oxford: Berg.

Bryceson, D. F. \& Vuorela, U. (2002b). Transnational families in the twentyfirst century. In: Bryceson, D. F. \& Vuorela, U. (Eds.), The transnational family. New European frontiers and global networks. Oxford: Berg, pp. 3-30.

Buber-Ennser, I., Kohlenberger, J., Rengs, B., Zalak, Z. al, Goujon, A., Striessnig, E., Potančoková, M., Gisser, R., Testa, M. R. \& Lutz, W. (2016). Human capital, values, and attitudes of persons seeking refuge in Austria in 2015. PloS one, 11, 9, e0163481. doi: 10.1371/journal.pone.0163481.

Carling, J. (2017). Refugee advocacy and the meaning of migrants. Oslo: Peace Research Institute Oslo (PRIO Policy Brief 2).

Cohen, R. (1997). Global diasporas. An introduction. Seattle: University of Washington Press.

Crawley, H. \& Skleparis, D. (2018). Refugees, migrants, neither, both: Categorical fetishism and the politics of bounding in Europe's 'migration crisis'. Journal of Ethnic and Migration Studies, 44, 1, pp. 48-64. doi: 10.1080/1369183X.2017.1348224.

Crespi, I., Giada Meda, S. \& Merla, L. (Eds.) (2018). Making multicultural families in Europe. Gender and intergenerational relations. Cham: Palgrave Macmillan UK.

DeJong, G. F. \& Gardner, R. W. (Eds.) (1981). Migration decision making. Multidisciplinary Approaches to microlevel studies in developed and developing countries. New York: Pergamon Press.

Elder, G. H. (Hrsg.) (1973). Linking social structure and personality. Beverly Hills: Sage.

Elder, G. H. (1974). Children of the Great Depression. Social change in life experience. Chicago, IL: University of Chicago Press.

Elder, G. H., Modell, J. \& Parke, R. D. (1993). Children in time and place. Developmental and historical insights. Cambridge, New York, NY: Cambridge University Press.

Elder, G. H., JR., Kirkpatrick Johnson, M. \& Crosnoe, R. (2003). The emergence and development of life course theory. In: Mortimer, J. T. \& Shanahan, M. J. (Eds.), Handbook of the life course. New York, pp. 3-19.

Faist, T. (2000). The volume and dynamics of international migration and transnational social spaces. Oxford, UK: Clarendon Press.

Giddens, A. (1984). The constitution of society. Outline of the theory of structuration. Cambridge, UK: Polity Press.

Giele, J. Z. \& Elder, G. H. (Eds.) (1998). Methods of life course research. Qualitative and quantitative approaches. Thousand Oaks: Sage.

Glick, J. E. (2010). Connecting complex processes: A decade of research on immigrant families. Journal of Marriage and Family, 72, 3, pp. 498-515.

Goulbourne, H., Reynolds, T., Solomos, J. \& Zontini, E. (2011). Transnational families. Ethnicities, identities and social capital. London: Routledge.

Grillo, R. D. (2008). The family in dispute: insiders and outsiders. In: Grillo, R. D. (Ed.), The family in question. Immigrant and ethnic minorities in multicultural Europe. Amsterdam: Amsterdam University Press, pp. 15-35.

Grillo, R. D. (Ed.) (2008). The family in question. Immigrant and ethnic minorities in multicultural Europe. Amsterdam: Amsterdam University Press.

Huinink, J. \& Feldhaus, M. (2009). Family research from the life course perspective. International Sociology, 24, 3, pp. 299-324. doi: 10.1177/0268580909102910. 
262 C. M. Aybek \& N. Milewski: Introduction: "Family migration processes in a comparative perspective"

Kasinitz, P., Waters, M. C., Mollenkopf, J. H. \& Anil, M. (2002). Transnationalism and the children of immigrants in contemporary New York. In: Levitt, P. \& Waters, M. C. (Eds.), The changing face of home: The transnational lives of the second generation. New York: Russell Sage Foundation, pp. 96-122.

Kibria, N. (2002). Of blood, belonging, and homeland trips. Transnationalism and identity among second-generation Chinese and Korean Americans. In: Levitt, P. \& Waters, M. C. (Eds.), The changing face of home: The transnational lives of the second generation. New York: Russell Sage Foundation, S. 295-311.

Kofman, E., Kraler, A., Kohli, M. \& Schmoll, C. (2011). Introduction. Issues and debates on familyrelated migration and the migrant family: A European Perspective. In: Kraler, A., Kofman, E., Kohli, M. \& Schmoll, C. (Eds.), Gender, generations and the family in international migration. Amsterdam: Amsterdam University Press, pp. 13-54.

Kohlenberger, J., Buber-Ennser, I., Rengs, B. \& Zalak, Z. al (2017). A social survey on refugees in and around Vienna in fall 2015: Methodological approach and field observations. Refugee Survey Quarterly, 36, 4, pp. 90-109. doi:10.1093/rsq/hdx012.

Kraler, A. (2014). A liberal paradox: Expanding rights, reducing access? Contemporary patterns of family migration policies in the EU. In: Geisen, T., Studer, T. \& Yildiz, E. (Eds.), Migration, Familie und Gesellschaft. Wiesbaden: Springer Fachmedien Wiesbaden, pp. 357-378.

Kulu, H. \& Milewski, N. (2007). Family change and migration in the life course: An introduction. Demographic Research, 17, 19, pp. 567-590. doi 10.4054/DemRes.2007.17.19.

Lamont, M. (2014). Reflections inspired by "Ethnic boundary making: Institutions, power, networks" by Andreas Wimmer. Ethnic and Racial Studies, 37, 5, pp. 814-819. doi:10.1080/01419870.2013.871312.

Lanzieri, G. (2012). Merging populations: A look at marriages with foreign-born persons in European countries. Luxembourg: Eurostat (Statistics in Focus 29).

Levitt, P., DeWind, J. \& Vertovec, S. (2003). International perspectives on transnational migration: An introduction. International Migration Review, 37, 3, pp. 565-575-5. https://doi.org/10.1111/j.1747-7379.2003.tb00150.x.

Levitt, P. \& Waters, M. C. (Eds.) (2002). The changing face of home. The transnational lives of the second generation. New York: Russell Sage Foundation.

Mau, S. (2007). Transnationale Vergesellschaftung. Frankfurt am Main: Campus Verlag.

Mortimer, J. T. \& Shanahan, M. J. (Eds.) (2003). Handbook of the life course. New York: Kluwer Academic/Plenum.

Nauck, B. (2005). Intergenerational relations in Turkish families in Germany. In: Pflegerl, J. (Ed.), Migration and the family in the European Union. Wien: Österreichisches Institut für Familienforschung (ÖIF), pp. 99-127.

Park, R. E. \& Burgess, E. W. (1921). Introduction to the science of sociology. Chicago,: University of Chicago Press.

Reed, H. E., Ludwig, B. \& Braslow, L. (2016). Forced migration. In: White, M. J. (Ed.), International handbook of migration and population distribution. Dordrecht: Springer Netherlands, pp. 605-625.

Schrover, M. (2009). Family in Dutch migration policy 1945-2005. The History of the Family, 14, 2, pp. 191-202. http://dx.doi.org/10.1016/j.hisfam.2009.03.002.

Smith, M. P. \& Guarnizo, L. (Eds.) (1998). Transnationalism from below. New Brunswick: Transaction Publishers.

Stark, O. \& Bloom, D. E. (1985). The new economics of labor migration. American Economic Review, 75,2 , pp. $173-178$.

Strasser, E., Kraler, A., Bonjour, S. \& Bilger, V. (2009). Doing family. Responses to the constructions of 'the migrant family' across Europe. The History of the Family, 14, 2, pp. 165-176.

Thomas, W. I. \& Znaniecki, F. (1918-1920). The Polish peasant in Europe and America. Boston: Badger, Gorham Press.

Vertovec, S. (2007). Super-diversity and its implications. Ethnic and Racial Studies, 30, 6, pp. 10241054. doi:10.1080/01419870701599465. 
Walter, A. (2009). Familienzusammenführung in Europa: Völkerrecht, Gemeinschaftsrecht, Nationales Recht. Baden-Baden: Nomos.

Williams, A. M. \& Baláž, V. (2012). Migration, risk, and uncertainty: theoretical perspectives. Populastion, Space and Place, 18, 2, pp. 167-180.

Williams, L. (2010). Global marriage. Cross-border marriage migration in global context. Basingstoke: Palgrave Macmillan.

Wimmer, A. (2008). Elementary strategies of ethnic boundary making. Ethnic and Racial Studies, 31, 6, pp. 1025-1055. https://doi.org/10.1080/01419870801905612.

Wimmer, A. (2013). Ethnic boundary making. Institutions, power, networks. Oxford, UK: Oxford University Press.

Addresses of the guest editors:

Can M. Aybek (Corresponding author)

Bremen City University of Applied Sciences/

Hochschule Bremen

Fakultät 3, Gesellschaftswissenschaften

Neustadtswall 30

28199 Bremen

Germany

Email: can.aybek@hs-bremen.de

Nadja Milewski

University of Rostock/Universität Rostock

Institut für Soziologie und Demographie

Ulmenstr. 69

D-18057 Rostock

Germany

Email: nadja.milewski@uni-rostock.de 